\title{
Restless nights, listless days
}

\author{
More and more people's working and social lives are blighted by skewed \\ sleep patterns. Is it time for the medical mainstream to take notice of what \\ neuroscientists are learning about the body clock? Alison Abbott reports.
}

A $s$ thousands of researchers from Europe and Asia join their American colleagues in New Orleans next week for the annual Society for Neuroscience conference, much of the café talk will revolve around jetlag and the merits of melatonin. Does taking this hormone really help us to adjust more quickly to a new time zone?

At least neuroscientists should be able to get an informed opinion. Their discipline includes specialists who study the body's daily, or circadian, rhythms. And the good news, from a recent analysis of the few studies that have investigated the effects of melatonin, is that it does help to reset weary travellers' body clocks ${ }^{1}$. The hormone is secreted from the brain's pineal gland during darkness, but levels fall when day breaks. It influences the body's 'master clock' - the suprachiasmatic nuclei (SCN) - located in a region of the brain called the hypothalamus. So by taking extra melatonin at the desired bedtime, you can retrain your clock more quickly to match the local time zone.
Jetlag is just one example of a disruption to circadian rhythms. Your body clock can be upset by disease, seasonal changes in day length, and even ageing — causing sleep patterns to shift from the norm. You can also run into problems if you try to ignore your biological rhythms, for example when working night shifts. But circadian biologists are finding that broken body clocks can, in some cases, be mended. They are now calling on governments to recognize the societal importance of their work, and to provide the funding needed to move the field from its current fringe status into the mainstream of medicine.

When your biological clock is running smoothly, body temperature and the levels of various hormones, such as cortisol, peak and trough in fixed cycles, synchronized to the onset of night and day (see diagram, opposite). Body temperature reaches a maximum in the early evening and then falls, generally dropping by a full degree centigrade by the end of a night's sleep. Many other physiological functions show similarly resilient rhythms. What's more, the basic tempo of the cycle is fixed - it can't get much faster or slower - even in the absence of external cues that signal the time of day.

The workings of circadian clocks are gradually being revealed, right down to their molecular nuts and bolts. Central to the timekeeping mechanism are the $\mathrm{SCN}$, which comprise two clusters of 50,000 neurons, one on each side of the brain. A dozen or so timekeeping genes - with names such as Period, Clock and Crytochrome - have been identified in the human SCN over the past few years. Together, they orchestrate the daily cycle of sleep and wakefulness. The genes are periodically switched on and off by complex feedback loops that are influenced by our exposure to light, which the SCN seem to sense through specialized neurons called melanopsin cells in the eye's retina. These are sensitive to blue light, but have nothing to do with vision ${ }^{2}$.

Circadian biologists are now beginning to understand what can go wrong with this system, and are figuring out how to put it 

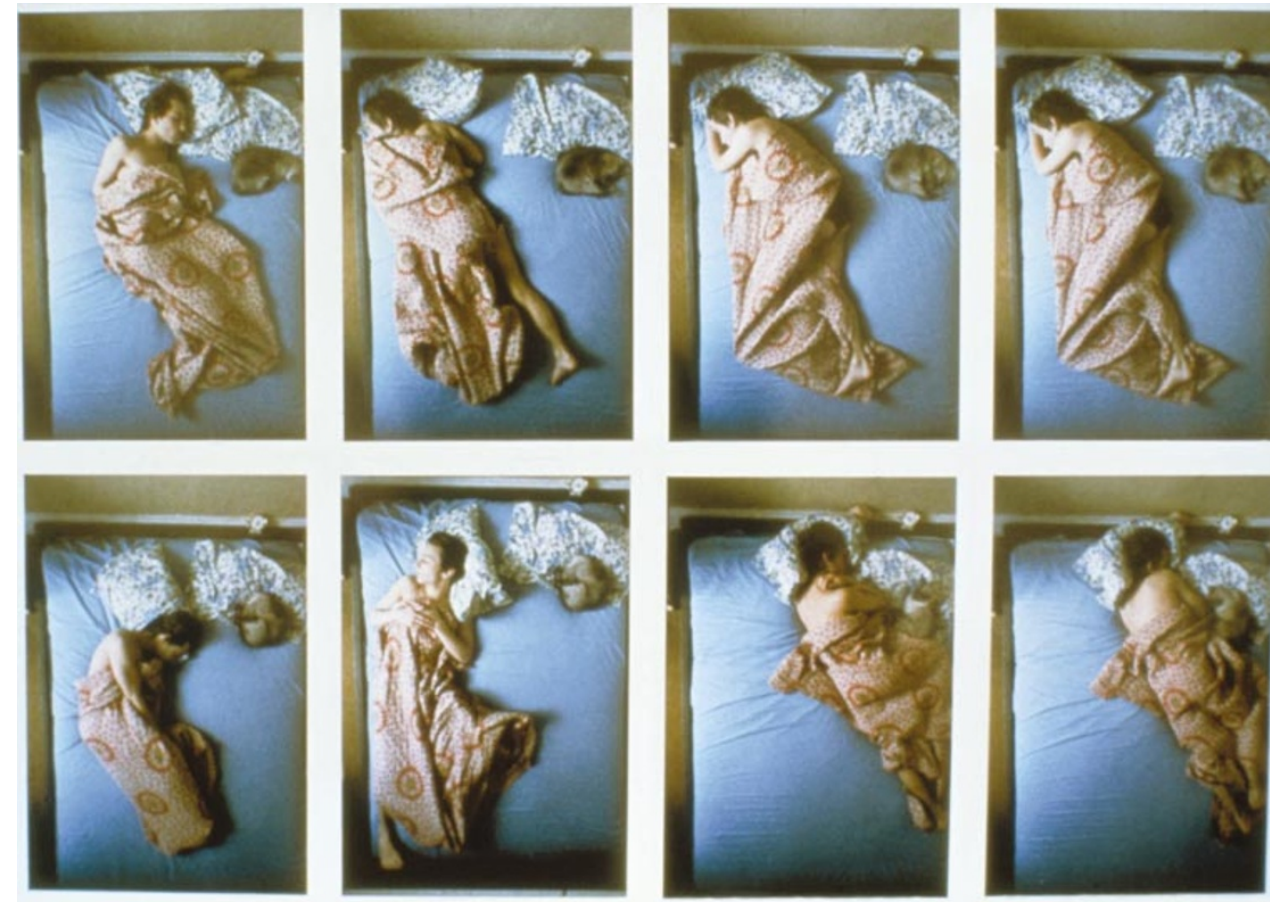

Tired and troubled: sleep researchers hope that better knowledge of the body clock's workings - and of how to influence its rhythm - will help those struggling with drowsy days and never-ending nights. right. Studies of the newly identified clock genes are already helping to reveal the causes of diseases that result in extremely unusual patterns of sleep and wakefulness (see 'Seriously out of synch', overleaf). And experts are now experimenting with light or melatonin as a fix for various circadian disruptions. For instance, Charles Czeisler, a sleep researcher at the Brigham and Women's Hospital in Boston, is testing blue light ${ }^{3}$ for resetting melatonin rhythms.

\section{Cycle paths}

Although everyone's rhythms operate on a daily cycle, our clocks can be set very differently, causing different people to be most active and alert at different times of the day. In general, we drift towards 'eveningness' during adolescence, and towards 'morningness' in old age. But our basic personal preferences are resilient: 'larks' who wake at
6 a.m. and 'owls' who never retire before 1 a.m. will remain as such, whatever the pressure from parents, spouses or employers ${ }^{4}$.

As well as being up with the larks, elderly people produce less melatonin overall, and therefore tend to have more disturbed sleep. But a team led by Kazuo Mishima, a sleep researcher at the National Center of Neurology and Psychiatry in Ichikawa, Japan, has shown that exposure to bright light in the middle of the day can increase night-time melatonin production and promote deep sleep for many old people. "In general, the more light old people have, the stronger their daily rhythms will be - and so their sleep patterns improve," says David Harper, a specialist in geriatric psychiatry at the McLean Hospital in Belmont, Massachusetts. "It is unfortunate that the old often live in poorly lit homes and don't get out much."

Adapting to normal signs of ageing is one
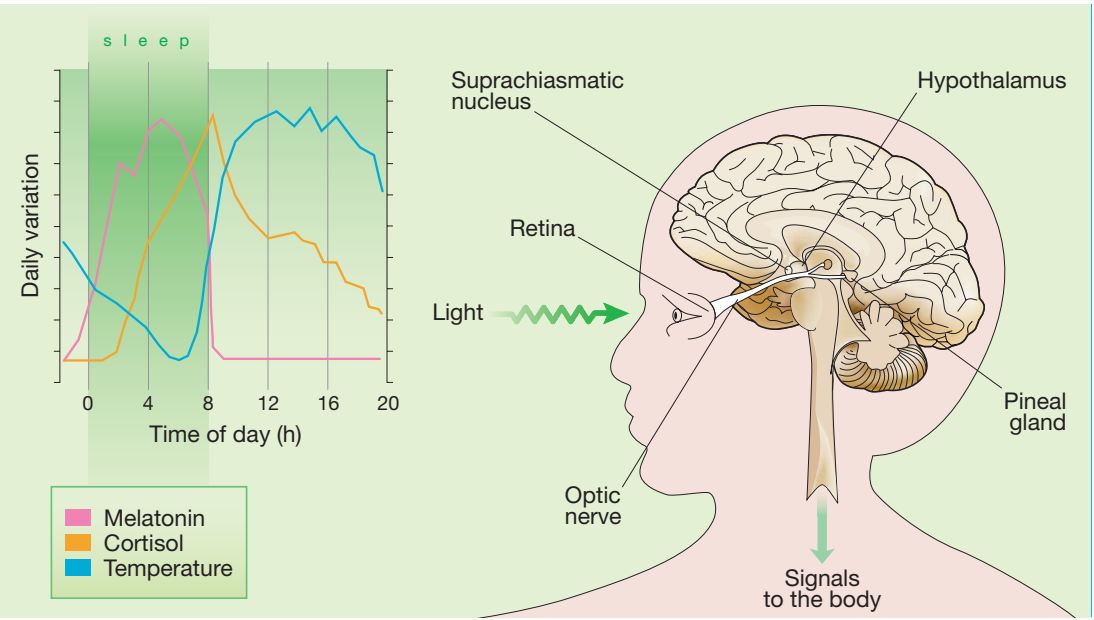

thing, but coping with the loss of active neurons from the SCN, as occurs in Alzheimer's disease for example ${ }^{6}$, is more challenging. The internal clock of an Alzheimer's patient may be out of synch with the actual cycle of day and night by several hours. "Normal old people, and old people with other types of dementia, hit their lowest body temperatures between 3 and 5 a.m.," says Harper, who has compared the circadian rhythms of patients with different dementias 7 . "But those with Alzheimer's frequently occur much later even as late as noon."

\section{Night nursing}

So Alzheimer's sufferers tend to be active when those who are caring for them want to sleep. "In fact, most Alzheimer's patients go into nursing homes not because of their memory disorders, but because families can't cope when they wander around at night," says Eus Van Someren of the Netherlands Institute of Brain Research in Amsterdam. He is on the verge of completing the first study to follow the progress of Alzheimer's patients exposed to different light conditions.

Earlier studies ${ }^{8}$ at the Amsterdam institute showed that exposing elderly rats suffering from loss of active SCN neurons and disturbed sleep patterns - to bright light restored both healthier sleep patterns and the number of active SCN neurons. "The neurons become inactive but don't disappear, and at least in the rat they can be reactivated," says Van Someren. "So we wondered if this 'use-it-or-lose-it' phenomenon could happen also in old and demented people."

In 1999, Van Someren and his colleagues began their long-term study of how light conditions affect Alzheimer's patients. It has involved 190 subjects in 12 Dutch residential homes installed with light boxes in the ceilings to mimic skylights. In half of the homes these remained bright during the day, whereas in control homes the lighting was kept low. The researchers measured the strength of the patients' biological rhythms every six months, and monitored their sleep over a two-week period using an activity monitor strapped to the wrist.

Van Someren is still analysing the data generated during the first three-and-a-half years of the study, but he reported his early findings to the 1st World Congress of Chronobiology in Sapporo, Japan, in September. Bright lighting during the day shifted circadian rhythms back towards a normal pattern, improving sleep patterns and mood. It also seemed to slow the decline in the patients' cognitive capacity.

Schizophrenics are similarly often active at night. "Psychiatrists have tended to dismiss this observation with the notion that 'they can't hold down a job, so of course they will be staying up all night'”, says Russell 
Foster, a circadian biologist at Imperial College, London. Foster and his colleague Katharina Wulff are now trying to find out whether schizophrenics have disrupted circadian rhythms. The eight individuals they have so far studied tended towards extreme eveningness, and the researchers are now applying to the UK Medical Research Council's new Brain Sciences Initiative for funding to study the effect of treating schizophrenics with light. "It will be interesting to see if consolidating sleep-wake profiles helps to control schizophrenic episodes," says Foster.

Light also helps to relieve the symptoms of depression that afflict patients with seasonal affective disorder. Also called the 'winter blues', the problem is clearly linked to disrupted circadian rhythms as the nights draw in". "Light-treatment results can be seen within a week — an advantage over classical antidepressants, which take several weeks to kick in", says Anna Wirz-Justice, a circadian biologist at the University of Basel. In Switzerland, at least, light therapy is paid for by medical insurance companies.

While scientists are finding that light or melatonin can help when daily biological rhythms are off-balance, they are also discovering the alarming extent to which modern society works against, rather than with, normal circadian biology. Employers, educators and politicians are only now realizing that there may be a serious issue to face.

Shift work is the most notorious example. Night-shift workers do not adjust their circadian rhythms because they are exposed

\section{Seriously out of synch}

\section{Imagine the impact on your working and social}

life if you regularly woke at $3 \mathrm{a} . \mathrm{m}$. and had to retire to bed by early evening. That is the burden of people with a rare inherited condition called familial advanced sleep phase syndrome (FASPS). Their problems lie with a circadian clock that is out of synch with the daily cycle of light and dark ${ }^{10}$.

Circadian biologists are now looking at genes that are known to influence our body clock, to see if they can explain such extreme sleep disorders. In one FASPS family, the cause turned out to be a mutation in the human Period2 gene ${ }^{11}$. "It doesn't explain all cases of FASPS because this mutation was found in only one of the 40 families we are looking at," says Louis Ptácek of the University of California, San Francisco, who led the study. His group is now sequencing all of the known clock genes in each of the families in the hope of finding other mutations related to the syndrome.

Children with the rare but very debilitating Smith-Magenis syndrome, caused by a deletion in chromosome 17 that results in severe mental retardation, also have unusual circadian rhythms. Their production of the clock-setting hormone melatonin during the 24-hour cycle is essentially

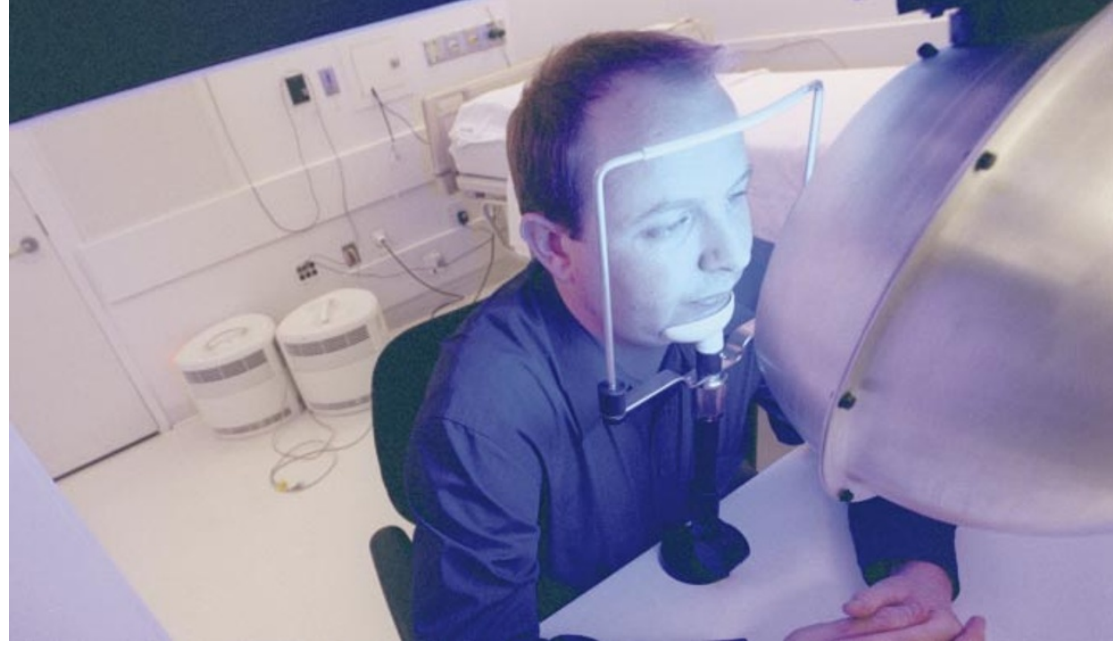

Out of the blue: doses of light therapy could boost production of hormones that set the body clock.

to daylight, particularly in summer, before and after their shifts. Small wonder, then, that productivity is lowest during night shifts. "So far, industry has not taken this seriously enough," says Till Roenneberg, a circadian biologist at the University of Munich, Germany.

\section{Driving progress}

Roenneburg is running the first large study — sponsored by the car manufacturer Volkswagen - to relate individual preferences for morningness and eveningness to physiology and performance under different factory light conditions. His team began by fitting some areas of Volkswagen's Wolfsburg plant with brighter lighting than usual, and then examined workers under controlled laboratory conditions before and after this intervention. The study, involving around 100

reversed, so they do not sleep at night and become hyperactive while trying to stay awake during the day.

Earlier this year, clinical geneticist Hélène de Leersnyder at the Necker Hospital for Sick Children in Paris showed that these children can be treated by giving them beta-blockers in the morning to block melatonin secretion, and then giving them melatonin itself in the evening ${ }^{12}$. "The children sleep more normally and their behaviour becomes more stable," she says. She is also looking for the deleted gene that may be responsible for their faulty clock.

Researchers led by Takashi Ebisawa, a neurogeneticist at Saitama Medical School in Japan, have found an association between the human Period3 gene and a disorder called delayed sleep phase syndrome (DSPS), in which those afflicted typically stay up until 4 or 5 a.m. Intriguingly, Malcolm von Schantz and his colleagues at the University of Surrey in Guildford, UK, have also found that normal preferences for 'morningness' and 'eveningness' are associated with variations in the same gene $^{13}$. Perhaps distressing conditions such as DSPS are just the extreme end of natural variation in the way our body clocks are set. workers, will be completed by next spring. "Volkswagen is in the vanguard, but other car companies are now showing a lot of interest in researching the night-shift problem," says Roenneberg.

Students would also benefit if greater attention were paid to their circadian biology. Roenneberg irritated local politicians last year by arguing publicly against early starts for school students - most German school days begin at 8 a.m., and some at 7 a.m. "We know that adolescents are shifted towards eveningness and are just not very alert early in the morning," he argues. In the United States, a bill has been introduced in the Congress proposing to reward schools that elect to delay starting times with grants of up to $\$ 25,000$.

Around the world, awareness of the social importance of circadian biology is slowly growing. Foster, for example, has been asked to discuss the subject with British Prime Minister Tony Blair. "The huge impact of circadian biology on health and wealth is starting to be appreciated by politicians," he says. In Japan, scientists are planning studies on the effects that brightly lit 24-hour shopping malls and late-night gaming arcades are having on daytime performance, particularly among the young.

Nevertheless, circadian biologists say that investment in their field lags behind that in disciplines with similar societal relevance. It is time, they suggest, for politicians and funding agencies to see the light.

Alison Abbott is Nature's senior European correspondent.

1. Herzheimer, A. \& Waterhouse, J. Br. Med. J. 326, 296-297 (2003).

2. Berson, D. M., Dunn, F. A. \& Takao, M. Science 295, 1070-1073 (2002).

3. Lockley, S. W., Brainard, G. C. \& Czeisler, C. A.

J. Clin. Endocrinol. Metab. 88, 4502-4505 (2003).

4. Roenneberg, T., Wirz-Justice, A. \& Merrow, M. J. Biol. Rhythms 18, 80-90 (2003).

5. Mishima, K., Okawa, M., Shimizu, T. \& Hishikawa, Y. J. Clin. Endocrinol. Metab. 86, 129-134 (2001)

6. Swaab, D. F., Fliers, E. \& Partiman, T. S. Brain Res. 342, 37-44 (1985).

7. Harper, D. G. et al. Arch. Gen. Psychiatry 58, 353-360 (2001)

8. Lucassen, P. J., Hofman, M. A. \& Swaab, D. F. Brain Res. 693 261-266 (1995)

9. Wirz-Justice, A. Arch. Gen. Psychiatry 55, 861-862 (1998).

10. Jones, C. R. et al. Nature Med. 5, 1062-1065 (1999).

11. Toh, K. L. et al. Science 291, 1040-1043 (2001).

12. De Leersnyder, H. et al. J. Med. Genet. 40, 74-78 (2003).

13. Archer, S. N. et al. Sleep 26, 413-415 (2003). 